\title{
Prevalence of attention-deficit/hyperactivity disorder (ADHD) symptoms in preschool children: discrepancy between parent and teacher evaluations
}

\author{
Yukio Soma $\cdot$ Kazutoshi Nakamura • \\ Mari Oyama $\cdot$ Yasuo Tsuchiya $\cdot$ Masaharu Yamamoto
}

Received: 1 October 2008/ Accepted: 22 December 2008/Published online: 16 January 2009

(C) The Japanese Society for Hygiene 2009

\begin{abstract}
Objective Clarifying the characteristics of attention-deficit/ hyperactivity disorder (ADHD) symptoms in childhood is important for the prevention and management of this disorder. The purpose of this study was to determine the prevalence of ADHD symptoms in Japanese preschool children based on evaluations performed by parents or teachers.

Methods A questionnaire survey was performed to evaluate the estimated prevalence of ADHD symptoms in preschool children in Niigata City, Japan. The first survey, conducted in 2003, involved an evaluation of ADHD symptoms by their school teachers. The second survey, conducted in 2006, involved an evaluation of the symptoms by parents. The teacher survey included 9,956 children, and the parent survey included 7,566 children. Parents and teachers assessed ADHD symptoms in children using a 14-item questionnaire based on DSM-III-R. Children with a score of 8 or higher were classified as having ADHD symptoms.

Results The overall prevalence of ADHD symptoms was $2,349 / 7,566(31.1 \%)$ in the parent survey and $431 / 9,956$ $(4.3 \%)$ in the teacher survey, with a prevalence ratio of 7.2 (95\% CI: 6.5-7.9). Likelihood ratio test indicated that variables significantly associated with the presence of ADHD symptoms were gender, age, school type, interaction between gender and observer, and interaction between school type and observer (each with $P<0.0001$ ).
\end{abstract}

Y. Soma · K. Nakamura $(\bowtie) \cdot$ M. Oyama · Y. Tsuchiya M. Yamamoto

Department of Community Preventive Medicine,

Niigata University Graduate School of Medical and Dental

Sciences, 1-757 Asahimachi-dori, Niigata 951-8510, Japan

e-mail: kazun@med.niigata-u.ac.jp
Conclusions The large difference between the estimated prevalence of ADHD symptoms in Japanese preschool children from teacher and parent surveys suggests that compared to teachers, parents consider their children's symptoms much more serious. Thus, parental evaluation of ADHD symptoms using DSM criteria may be inappropriate for ADHD screening.

Keywords Attention-deficit/hyperactivity disorder (ADHD) · Epidemiology · Japan · Preschool children · Prevalence

\section{Introduction}

Attention-deficit/hyperactivity disorder (ADHD) in children is a rising public health concern. This disorder, which is characterized by inappropriate levels of inattention, impulsiveness, and hyperactivity [1], is often associated with impairment in daily functions at home and school.

The prevalence of ADHD-related behavior, or ADHD symptoms, has been estimated by epidemiological studies to range widely from 2 to $18 \%$ in Western countries, and the prevalence of ADHD appears to be increasing in these areas [2]. Few population-based epidemiological studies on ADHD symptoms have been conducted in Japan [3]. One such study found that $4.3 \%$ of preschool children had ADHD symptoms, based on evaluation by teachers in school settings [4].

In general, ADHD symptoms become noticeable in primary school. However, in half of ADHD cases, this disorder is onset before the age of four [1], which has led to the hypothesis that ADHD is a developmental disorder [2]. We therefore surmised that a thorough understanding of epidemiologic features of ADHD symptoms in preschool children is important to prevent and manage this disorder. 
ADHD symptoms can manifest to different degrees in a variety of environments, including at home, school, and other social situations. Thus, the ability to diagnose these symptoms in multiple settings is important [1]. However, the estimated prevalence of ADHD symptoms may depend on the setting (home or school) and the person conducting the evaluation (parent or teacher). The aim of this study was to determine the prevalence of ADHD symptoms in Japanese preschool children based on evaluations by parents and teachers. Since the disorder is generally diagnosed in the clinical setting, this paper uses the term "ADHD symptoms" to refer to ADHD diagnosed in non-clinical settings.

\section{Methods}

\section{Study design}

Questionnaire surveys were performed to evaluate the estimated prevalence of ADHD symptoms in two different cohorts of Japanese preschool children. The first survey, conducted in 2003, involved an evaluation of children for ADHD symptoms by school teachers. The second survey, conducted in 2006, involved an evaluation of the children by their parents using a similar methodology. These two surveys will be referred to as the teacher and parent surveys in this paper. The study protocol was approved by the Ethics Committee of Niigata University School of Medicine.

\section{Study population}

Children between the ages of three and six attending kindergarten or nursery school in Niigata City, Japan, participated in the study. For the teacher survey, 25 of 40 kindergartens and 85 of 112 nursery schools agreed to participate, resulting in a total of 9,956 children $(4,076$ from kindergarten and 5,880 from nursery school). For the parent survey, 26 of 38 kindergartens and 95 of 107 nursery schools agreed to participate. Of the 4,370 children in the 26 kindergartens and 5,821 in the 95 nursery schools, 3,369 parents of the children (participation rate $77.1 \%$ ) from kindergarten and 4,197 (participation rate $72.1 \%$ ) from nursery school agreed to participate.

Outcome and explanatory variables

A 14-item observer-rating questionnaire was generated to assess ADHD symptoms in children within the last 6 months. The questionnaire was based on the Japanese version [5] of the Diagnostic and Statistical Manual of Mental Disorders, 3rd Edition-Revised (DSM-III-R) [1] (Appendix 1). The three possible responses to each item were "always," "sometimes," and "rarely or none." For the analysis, "always" and "sometimes" were grouped and coded as 1, while "rarely or none" was coded as 0 . This questionnaire was used in both the teacher and parent surveys to assess ADHD behavior in participating children. Children with a score of 8 or higher were classified as having ADHD symptoms [1]. In addition, the gender and age (preschool year) of each child was recorded.

\section{Statistical analyses}

The prevalence of ADHD symptoms was calculated for the parent and teacher surveys. The relative prevalence between the surveys, presented as a prevalence ratio, was also calculated. The difference in prevalence between the two groups was assessed using the $\chi^{2}$ test for bivariate analysis. Multiple logistic regression was used to test for a linear trend in the prevalence across the three age groups. In our study, the three age groups were stratified by preschool year, i.e., the "4-year-old" group included 3- or 4-year-old children, the "5-year-old" group included 4- or 5-year-old children, and the "6-year-old" group included 5- or 6-yearold children. Multiple logistic regression analysis (PROC LOGISTIC) was used to determine adjusted odds ratios. Likelihood ratio test (PROC GENMOD) was used to assess interactions of explanatory variables with the multivariate model, which included four explanatory variables (gender, age, school type, and observer) and interaction terms (parent or teacher) for each of the first three variables. Statistical analyses were conducted using the SAS statistical package (release 8.02, SAS, Cary, NC, USA). $P$ values of less than 0.05 were considered statistically significant.

\section{Results}

The prevalence of ADHD symptoms by gender from the parent and teacher surveys is shown in Table 1. The overall and gender-specific prevalences in the parent survey were higher than those in the teacher survey. The difference in prevalence of symptoms between boys and girls was statistically significant in both the parent and teacher surveys $(P<0.0001)$. Similarly, when the results were stratified by age, the prevalence was higher in the parent survey for all

Table 1 Gender-specific prevalence of ADHD symptoms in children from the parent and teacher surveys

\begin{tabular}{lrrc}
\hline Parent survey & Teacher survey & $\begin{array}{l}\text { Prevalence ratio } \\
(95 \% \mathrm{CI}) \text { (parents/ } \\
\text { teachers) }\end{array}$ \\
\hline Boys & $1,397 / 3,861(36.2 \%)$ & $358 / 5,114(7.0 \%)$ & $5.2(4.6-5.8)$ \\
Girls & $952 / 3,705(25.7 \%)$ & $73 / 4,842(1.5 \%)$ & $17.0(13.5-21.5)$ \\
Total & $2,349 / 7,566(31.1 \%)$ & $431 / 9,956(4.3 \%)$ & $7.2(6.5-7.9)$ \\
\hline
\end{tabular}


Table 2 Age-specific prevalence of ADHD symptoms in children from the parent and teacher surveys

\begin{tabular}{llll}
\hline & Parent survey & Teacher survey & $\begin{array}{l}\text { Prevalence ratio } \\
\text { (95\% CI) (parents/teachers) }\end{array}$ \\
\hline 4-year-old children (3 or 4 years old ${ }^{\mathrm{a}}$ ) & $742 / 2,080(35.7 \%)$ & $181 / 3,223(5.6 \%)$ & $6.4(5.5-7.4)$ \\
5-year-old children (4 or 5 years old $\left.{ }^{\mathrm{a}}\right)$ & $811 / 2,577(31.5 \%)$ & $149 / 3,333(4.5 \%)$ & $7.0(6.0-8.3)$ \\
6-year-old children (5 or 6 years old $\left.{ }^{\mathrm{a}}\right)$ & $796 / 2,909(27.4 \%)$ & $101 / 3,400(3.0 \%)$ & $9.2(7.5-11.3)$ \\
\hline
\end{tabular}

${ }^{\text {a }}$ Age is stratified by preschool year. The actual ages of the children in this group are given in parentheses

Table 3 School-specific prevalence of ADHD symptoms in children from the parent and teacher surveys

\begin{tabular}{lrrl}
\hline & Parent survey & Teacher survey & $\begin{array}{l}\text { Prevalence ratio } \\
(95 \% \text { CI) (parents/teachers) }\end{array}$ \\
\hline Kindergarten & $920 / 3,369(27.3 \%)$ & $93 / 4,076(2.3 \%)$ & $12.0(9.7-14.7)$ \\
Nursery school & $1,428 / 4,197(34.0 \%)$ & $338 / 5,880(5.8 \%)$ & $5.9(5.3-6.6)$ \\
\hline
\end{tabular}

age groups (Table 2). This was reflected in estimates of the relative prevalence, with a prevalence ratios ranging from 6.4 for the age group to 9.2 for the oldest. In both surveys, the prevalence of ADHD symptoms was lower in older age groups $(P<0.0001)$.

Table 3 presents the estimated prevalence of ADHD symptoms by school type (kindergarten and nursery) from the parent and teacher surveys. Similar to the age and gender results, the prevalence of ADHD symptoms was higher in the parent survey for both school types. The difference in prevalence between kindergartens and nursery schools was also statistically significant in both surveys $(P<0.0001)$.

Results from the multiple logistic regression analysis are displayed in Table 4. This analysis indicated that gender, age, school type, and observer type were all independent explanatory variables. Results of likelihood ratio test are shown in Table 5. The interactions between gender and observer type and between school and observer type were statistically significant. This implies that the relative prevalences between surveys for boys (prevalence ratio $=5.2$ ) and girls (prevalence ratio $=17.0$ ) were significantly different (Table 1). Similarly, the relative prevalences for kindergartens (prevalence ratio $=12.0$ ) and nursery schools (prevalence ratio $=5.9$ ) were also significantly different (Table 3).

\section{Discussion}

Studies have shown that the estimated prevalence of ADHD symptoms differs depending on the study methodology, diagnostic criteria, and demographic characteristics of the population, such as ethnicity, gender, and age $[6,7]$. Prevalence also differs depending on the person evaluating the symptoms, such as the parent, teacher, or child [8]. The present study focuses on some of these differences in Japanese preschool children.
Table 4 Results of multiple logistic regression analysis (outcome is the presence of ADHD symptoms)

\begin{tabular}{lll}
\hline Explanatory variables & $\begin{array}{l}\text { Adjusted odds ratio } \\
(95 \% \text { CI })\end{array}$ & $P$ value \\
\hline Observer (teacher, 0; parent, 1) & $10.9(9.8-12.2)$ & $<0.0001$ \\
Gender (girl, 0; boy, 1) & $2.0(1.8-2.2)$ & $<0.0001$ \\
Age (preschool year) & $0.79(0.75-0.84)$ & $<0.0001$ \\
$\begin{array}{l}\text { School type (kindergarten, 0; } \\
\text { nursery school, 1) }\end{array}$ & $1.5(1.4-1.7)$ & $<0.0001$ \\
\hline
\end{tabular}

Table 5 Results of likelihood ratio test (outcome is the presence of ADHD symptoms)

\begin{tabular}{lclll}
\hline Explanatory variables & $\begin{array}{l}\text { Parameter } \\
\text { estimate }\end{array}$ & $\begin{array}{l}\text { Standard } \\
\text { error }\end{array}$ & $\chi^{2}$ & $P$ value \\
\hline $\begin{array}{l}\text { Gender (girl, 0; boy, 1) } \\
\begin{array}{l}\text { Observer (teacher, 0; } \\
\text { parent, 1) }\end{array}\end{array}$ & 1.59 & 0.13 & 194.5 & $<0.0001$ \\
$\begin{array}{l}\text { School type (kindergarten, } \\
\text { 0; nursery school, 1) }\end{array}$ & 0.95 & 0.12 & 71.9 & $<0.0001$ \\
$\begin{array}{l}\text { Age (preschool year) } \\
\begin{array}{l}\text { Interaction between gender } \\
\text { and observer }\end{array}\end{array}$ & -0.30 & 0.06 & 23.9 & $<0.0001$ \\
$\begin{array}{l}\text { Interaction between school } \\
\text { type and observer }\end{array}$ & -0.63 & 0.14 & 70.5 & $<0.0001$ \\
$\begin{array}{l}\text { Interaction between age } \\
\text { and observer }\end{array}$ & 0.10 & 0.07 & 11.1 & $<0.0001$ \\
\hline
\end{tabular}

The results from this work indicate a marked difference in the prevalence of ADHD symptoms when the evaluation was performed by parents compared to teachers; the prevalence was consistently higher in the parent survey. This finding is in agreement with a study on Japanese school children in which the mean scores for the Child Behavior Checklist, which assesses behavioral and emotional problems, were higher for parents than teachers [9]. A possible explanation for this discrepancy is that parents 
may expect their children to be well-behaved and obedient, thus evaluating their behavior more strictly. This expectation may be especially high for parents of girls, which would explain why the relative prevalence is significantly higher for girls than boys based on parent versus teacher evaluations. This finding supports our hypothesis. Second, parents of preschool children may have difficulty determining whether a child's behavior is abnormal, thus resulting in more false positives in the parent survey. Third, children tend to behave more freely at home than at school, which may lead observers to conclude children are more symptomatic of ADHD. Finally, another explanation may be that mothers of preschool children may have great childrearing stress, which could lead to an induced diagnosis of ADHD symptoms. The primary person in charge of child rearing was not asked in the questionnaire. However, in most cases in Japan, this is most likely to be the mother, and thus this explanation is plausible.

While studies have shown that the prevalence of ADHD can be affected by the observer, the large differences found in this study are not typical. Pierrehumbert et al. [8] reported no difference in the prevalence of ADHD symptoms in school-aged Swiss children between parent (8.0\%) and teacher $(9.6 \%)$ evaluations, using the clinical cutoff point for the ADHD index. Erşan et al. [10] found no significant difference in ADHD symptoms of school-aged Turkish children, using DSM-IV criteria, based on parent (9.6\%) and teacher $(7.3 \%)$ evaluations. Furthermore, Polanczyk and Jensen [7] retrieved 71 studies during a recent systematic review of epidemiological studies on ADHD published in the last decade. The prevalence of ADHD symptoms was evaluated by parents in 24 studies and by teachers in 10 studies, with median prevalences of 5.3 and $10.3 \%$, respectively. Thus, our findings are not consistent with previous studies. This inconsistency may be explained by the two factors: a young-aged group (preschool children) of our study and cultural differences. We targeted preschool children, for whom ADHD symptom diagnosis may be more difficult than in school-aged children. In addition, Japanese parents may be more likely to regard their children's behavior as hyperactive than parents of other countries, which is in agreement with data from Satake et al. [9]. Unlike parents in Western cultures, Japanese parents often expect their children to act more grown up, and evaluate their children's behavior strictly. This expectation may be associated with the relatively high ADHD symptoms diagnosed by Japanese parents.

In this study, the relative prevalence of ADHD symptoms evaluated by parents compared to teachers was significantly higher for children in kindergartens than in nursery schools. This difference may be associated with the school environment. Kindergarten is a preschool that provides more educational programs than a nursery school.
Parents of children in kindergarten may therefore expect their children to be more well-behaved and obedient, thus potentially leading to an increased diagnosis of ADHD symptoms due to raised expectations. Another explanation may be that mothers of children in kindergartens have longer child-rearing times, and thus the proportion of those who work may be lower than that of mothers of children in nursery schools. Greater parental child-rearing stress in mothers of children in kindergartens may be associated with an increased prevalence ratio of ADHD symptoms (Table 3). In addition, the difference in prevalence between school types may be confounded by other factors such as familial environment and socioeconomic status, which are known risk factors for ADHD [11, 12]. These hypotheses should be tested in future studies.

Only one previous study appears to examine the prevalence of ADHD symptoms in preschool versus school children in Japan. Kanbayashi et al. [13] reported that the prevalence of ADHD symptoms in boys and girls, based on evaluation by parents using DSM-III-R criteria, were 12.6 and $10.1 \%$ in preschool children (4-6 years old), 13.7 and $2.5 \%$ in school children in lower grades (7-9 years old), and 5.5 and $2.3 \%$ in school children in upper grades (1012 years old), respectively. The study suggested that the prevalence rate of ADHD symptoms decreased as grade level increased, and this trend was especially true for girls. Furthermore, they suggested that the gender difference in prevalence from the parent evaluation was small, which is in accordance with our findings.

A recent systematic review indicated that the estimated worldwide prevalence of ADHD symptoms is $5.3 \%$, with $7 \%$ for children and 4\% for Asians. The review also found that studies relying on evaluation of symptoms by parents had higher prevalence rates [14]. In our study, the overall prevalence of ADHD symptoms from teacher evaluations was $4.3 \%$. These results suggest that results from the teacher survey may be more reflective of the true value compared to those from the parent survey, although some false positives and negatives are likely in the former survey.

The present study used a questionnaire based on DSMIII-R criteria to determine the prevalence of ADHD symptoms. Previous studies indicate that the prevalence of ADHD symptoms increases when switching from DSMIII-R to DSM-IV [6]. For example, Wolraich et al. [15] estimated the prevalence of ADHD symptoms to be $7.3 \%$ using DSM-III-R criteria and $11.4 \%$ with DSM-IV criteria. Thus, the prevalence of ADHD symptoms in this study might have been higher if DSM-IV criteria had been used.

A key limitation of this work was the use of different study populations for the parent and teacher surveys. Furthermore, parents were surveyed 3 years after the teachers. A higher prevalence of ADHD symptoms evaluated by parents might have been partly attributed to the time lag 
between the two surveys. Thus, the prevalence estimates from the two surveys may not be directly comparable, resulting in potentially biased estimates of prevalence ratios. Additionally, this limitation also prevented the assessment of cross-informant agreement. Other studies have found relatively low agreement between parents and teachers. For example, the agreement rate was found to be between 0.16 and 0.36 by Satake et al. [9] for the Child Behavior Checklist and 0.43 by Pierrehumbert et al. [8] using the ADHD index.

In summary, our findings suggest a large discrepancy in the prevalence of ADHD symptoms in preschool children based on evaluation by parents or teachers. The results imply that compared to teachers, parents consider their children's symptoms much more serious. Thus, using parents to diagnose ADHD symptoms based on DSM criteria may be inappropriate for ADHD screening. However, since the diagnosis of ADHD should be performed in multiple settings, alternative methods of evaluating a child's behavior at home need to be developed.

Acknowledgements We would like to thank all participating kindergartens and nursery schools for their assistance with data collection. The authors report no conflicts of interest.

\section{Appendix 1}

The 14-item questionnaire, based on DSM-III-R, which was used to assess ADHD-related behavior in children in the parent and teacher surveys is as follows:

1. Does the child often fidget with hands or feet or squirm in the seat?

2. Does the child have difficulty remaining seated when required to do so?

3. Is the child easily distracted by extraneous stimuli?

4. Does the child have difficulty awaiting turn in games or group situations?

5. Does the child often blurt out answers to questions before they have been completed?

6. Does the child have difficulty following through on instructions from others (not due to oppositional behavior or failure of comprehension), e.g., fails to finish chores?

7. Does the child have difficulty sustaining attention in tasks or play activities?

8. Does the child often shift from one uncompleted activity to another?

9. Does the child have difficulty playing quietly?

10. Does the child often talk excessively?

11. Does the child often interrupt or intrude on others, e.g., butts into other children's games?

12. Does the child often seem not to listen to what is being said to him or her?
13. Does the child often lose things necessary for tasks or activities at school or at home (e.g., toys, pencils, books, assignments)?

14. Does the child often engage in physically dangerous activities without considering possible consequences (not for the purpose of thrill-seeking), e.g., runs into street without looking?

\section{References}

1. American Psychiatric Association. Diagnostic and Statistical Manual of Mental Disorders (Third Edition-Revised). Washington, DC: American Psychiatric Association; 1987.

2. Rowland AS, Lesesne CA, Abramowitz AJ. The epidemiology of attention-deficit/hyperactivity disorder (ADHD): a public health view. Ment Retard Dev Disabil Res Rev. 2002;8:162-70.

3. Yoshimasu K, Yamashita H, Kiyohara C, Miyashita K. Epidemiology, treatment and prevention of attention deficit/hyperactivity disorder: a review (in Japanese). Nippon Koshu Eisei Zasshi. 2006;53:398-410.

4. Soma Y. A study on attention-deficit hyperactivity disorder (ADHD) at nursery school and kindergarten in Niigata City (in Japanese). Niigata Med J. 2006;120:324-8.

5. American Psychiatric Association. Diagnostic and Statistical Manual of Mental Disorders (Third Edition-Revised) (in Japanese). Igaku-Shoin, Tokyo, 1988.

6. Cuffe SP, Moore CG, McKeown RE. Prevalence and correlates of ADHD symptoms in the national health interview survey. J Atten Disord. 2005;9:392-401.

7. Polanczyk G, Jensen P. Epidemiologic considerations in attention deficit hyperactivity disorder: a review and update. Child Adolesc Psychiatr Clin N Am. 2008;17:245-60.

8. Pierrehumbert B, Bader M, Thévoz S, Kinal A, Halfon O. Hyperactivity and attention problems in a Swiss sample of school-aged children: effects of school achievement, child gender, and informants. J Atten Disord. 2006;10:65-76.

9. Satake H, Yoshida K, Yamashita H, Kinukawa N, Takagishi T. Agreement between parents and teachers on behavioral/emotional problems in Japanese school children using the child behavior checklist. Child Psychiatry Hum Dev. 2003;34:111-26.

10. Erşan EE, Doğan O, Doğan S, Sümer H. The distribution of symptoms of attention-deficit/hyperactivity disorder and oppositional defiant disorder in school age children in Turkey. Eur Child Adolesc Psychiatry. 2004;13:354-61.

11. Scahill L, Schwab-Stone M. Epidemiology of ADHD in schoolage children. Child Adolesc Psychiatr Clin N Am. 2000;9:541-55.

12. Froehlich TE, Lanphear BP, Epstein JN, Barbaresi WJ, Katusic SK, Kahn RS. Prevalence, recognition, and treatment of attention-deficit/hyperactivity disorder in a national sample of US children. Arch Pediatr Adolesc Med. 2007;161:857-64.

13. Kanbayashi Y, Nakata Y, Fujii K, Kita M, Wada K. ADHD-related behavior among non-referred children: parents' ratings of DSMIII-R symptoms. Child Psychiatry Hum Dev. 1994;25:13-29.

14. Polanczyk G, de Lima MS, Horta BL, Biederman J, Rohde LA. The worldwide prevalence of ADHD: a systematic review and metaregression analysis. Am J Psychiatry. 2007;164:942-8.

15. Wolraich ML, Hannah JN, Pinnock TY, Baumgaertel A, Brown J. Comparison of diagnostic criteria for attention-deficit hyperactivity disorder in a county-wide sample. J Am Acad Child Adolesc Psychiatry. 1996;35:319-24. 